\title{
GESTÃO SUSTENTÁVEL DE UNIDADES DE CONSERVAÇÃO: O CASO DA APA ESTADUAL DO RIO PANDEIROS, MINAS GERAIS
}

\author{
MARIA BÁRBARA DE MAGALHÃES BETHONICO \\ Universidade Federal de Roraima \\ SANDRA BATISTA DA CUNHA \\ Universidade Federal Fluminense
}

\section{Introdução}

Este artigo tem o propósito de colaborar com as reflexões sobre a necessidade de incluir as comunidades na gestão de uma Unidade de Conservação - UC, seja para a implementação da área como para elaboração e definição de ações para seu manejo sustentável. As dificuldades das famílias de se sustentarem no interior de uma UC, pela não adaptação às novas normas que restringem o uso do solo e dos recursos naturais disponíveis, são entendidas aqui como principais entraves para a efetivação do plano de manejo de uma UC de uso sustentável.

Sustentabilidade ambiental, desenvolvimento social e crescimento econômico não caminham juntos na maioria das vezes, apontando para a difícil tarefa de gestão de uma área que tem como finalidade a sustentabilidade, mas tem em seu interior a face mais agressiva da produção - a ilegal, que se aproveita da carência dos moradores locais. Essa é a situação da Área de Proteção Ambiental Estadual do Rio Pandeiros, que possui no seu interior e no entorno a produção de carvão vegetal sem autorização do órgão ambiental. $O$ carvoejamento $e$ as dificuldades da produção agrícola aparecem como os principais problemas na gestão da área, a ser efetivada pelo Instituto Estadual de Florestas de Minas Gerais. 
O controle desses problemas é denominado manejo de áreas. De acordo com Morsello (2001) os países em desenvolvimento enfrentam sérios problemas na efetivação desses planos de manejo, fazendo com que essas unidades de conservação sejam reconhecidas como "parques de papel", isto é, são áreas instituídas legalmente, mas que têm seus princípios comprometidos pela ausência de um programa de manejo.

Mesmo enquanto áreas protegidas, as pressões são constantes e bastante variadas, de acordo com as possibilidades de contribuição para um mercado consumidor, como comércio ilegal de animais da fauna silvestre, introdução de espécies exóticas ou, no caso desta pesquisa, a produção de carvão para atender à siderurgia. Assim, o fato de estar oficialmente protegida, com todo o aparato legal, não garante estar adequadamente preservada ou não ser manejada de forma a garantir a manutenção de seus ecossistemas.

É importante não apenas realizar levantamentos das ameaças a essas áreas, mas é de fundamental importância conhecer as causas para que o plano de manejo seja efetivamente praticado. Morsello (2001), em sua abordagem, esclarece que existem vários projetos de pesquisa em unidades de conservação, mas que muitos são direcionados apenas para os aspectos biológicos, sendo de fundamental importância a existência de pesquisas que abordem aspectos sociais constituindo, juntos, elementos que subsidiem a elaboração dos planos de manejo, em ações conjuntas envolvendo gerenciadores e cientistas. Dessa forma, torna-se importante conhecer o homem que está em contato direto com a Unidade de Conservação para que seja envolvido nas ações de conservação.

\section{Gestão pública de Unidades de Conservação: um desafio}

Com a inclusão das questões ambientais na pauta das discussões dos problemas que afetam a humanidade, principalmente nas últimas décadas do século XX, sucedeu-se uma série de demarcações de áreas de preservação e conservação ambientais. Em unidades classificadas como de uso sustentável (Lei $\mathrm{n}^{\circ}$ 9.985/2000, Art. 14) ocorre a dificuldade de ajustar a conservação da natureza e o uso de parte dos recursos naturais com a sobrevivência das comunidades ali presentes, considerando que a legislação ambiental brasileira define critérios para o uso da terra e dos recursos. Cabe ao Estado, no caso de unidades públicas, a função de buscar 
ações que garantam a sustentabilidade desses espaços através dos planos de manejo, incluindo projetos como os de produção agrícola, artesanato ou outros meios que possam garantir a sobrevivência dos moradores no processo de adaptação à legislação ambiental e as restrições para uso de suas terras.

$\mathrm{Na}$ implantação de políticas públicas ocorre, muitas vezes, a desconsideração do papel desse espaço para as comunidades ali presentes, anulando sua importância (STEINBERGER, 2006). O espaço é o palco onde as interações ocorrem. O homem faz parte juntamente com os outros elementos da natureza desse espaço, porém é ele que, através de suas ações e dos objetos técnicos, organiza o espaço num processo de conversão do meio geográfico em meio de modo de vida (MOREIRA, 2006). Quando o espaço é definido e delimitado por relações de poder, transforma-se em território, interessando quem domina ou influencia um determinado espaço. Nessa visão, o território é essencialmente um instrumento de exercício de poder (SOUZA, 2001).

Esse poder que caracteriza o território pode ser exercido por diferentes atores, tanto um cidadão quanto o Estado, sendo este entendido como um grupo de pessoas designada para controlar, direta ou indiretamente, alguma atividade ou um espaço, com base em valores reais ou socialmente reconhecidos (FGV, 1986).

O Estado tem um papel fundamental na estruturação dos territórios. As políticas públicas devem ter o cuidado de não se tornarem centralizadoras, efetuando um planejamento autoritário, quando as metas e recursos se destinam a um público alvo, mas que são atreladas ao planejamento imposto pelo Estado. Devem reconhecer a existência de poderes plurais, sejam federativos ou de novos sujeitos sociais expressos nos movimentos populares, de forma que o "Estado, gestor dos conflitos e articulador de interesses dos vários segmentos da sociedade, comanda essas políticas que, por serem públicas, envolvem os mais diversos interesses dos atores sociais" (STEINERGER, 2006:12). Assim, aponta para a necessidade de repensar a inserção do território e do ambiente na elaboração e execução de políticas públicas atuais, considerando-se políticas anteriores que inseriram no espaço objetos e ações, principalmente para as que privilegiavam apenas programas e projetos pontuais, com objetivos direcionados e setoriais, ficando as questões sociais e das comunidades locais à margem dessas políticas. 
Mesmo em projetos mais amplos a comunidade, muitas vezes, não é considerada em suas especificidades. Com isso, projetos que apresentam boas propostas quando são implementados não alcançam os objetivos junto à comunidade. Dessa forma, deixam de cumprir um dos princípios de uma política pública que é a eficiência na obtenção de resultados dos investimentos empregados, mesmo considerando as variações da noção de eficiência ao longo do processo histórico. Assim,

a análise das Políticas Públicas, atualmente exige pensar como a questão da eficiência se coloca no âmbito do capitalismo. Isto porque hoje esta noção está fortemente vinculada ao debate sobre o público e o privado e à incorporação da lógica destes às ações do primeiro. Faz-se necessário também entender a forma de organização do processo decisório, vendo-o como um conjunto estruturado de decisões com vistas a alcançar a maximização que, do ponto de vista das empresas, significa maior lucratividade e, do ponto de vista do Estado, alcance de determinados resultados (GUILHON e PEREIRA, 2002:104).

Um espaço ocupado por uma comunidade possui uma história. O resgate dessa história permite compreender a organização do território, os objetos e as relações ali presentes que lhe conferem um dinamismo próprio. Segundo Santos:

a ação é tanto mais eficaz quanto os objetos são mais adequados. Então, à intencionalidade da ação se conjuga a intencionalidade dos objetos e ambas são, hoje, dependentes da respectiva carga de ciência e técnica presente no território [...] os resultados da ação humana não dependem unicamente da racionalidade da decisão e da execução. Há sempre, uma quota de imponderabilidade no resultado, devida, por um lado, à natureza humana e, por outro lado, ao caráter humano do meio (SANTOS, 2002:94).

Ocorre, assim, a imprevisibilidade de uma ação que, mesmo tendo autonomia por fazer parte de um projeto mais amplo, pode ter um resultado diverso do esperado. A consequência disso é o descrédito da comunidade frente ao Estado e suas propostas. 
A conservação da biodiversidade no Brasil está diretamente relacionada à adoção de políticas públicas eficientes, capaz de reverter o quadro de inexistência de articulação na sua elaboração e implementação. Destaca-se o papel das comunidades locais (VALLEJO, 2005; AMARAL, 2007), em que a abordagem da questão ambiental deve partir, também, da investigação do comportamento das unidades familiares envolvidas com a agricultura, uma vez que essas pessoas participam da conservação informal das áreas por dependerem delas para a sobrevivência.

É importante discutir a temática das Unidades de Conservação no Brasil, através do emprego das múltiplas abordagens espaciais e territoriais, de forma integrada. Nesse contexto, alguns progressos já estão em curso, pois, segundo Vallejo (2005), o ambientalismo está se expandindo e tornando-se mais concreto através da formação de uma rede de informações que agrega novos membros das áreas acadêmicas e do público em geral, num processo de democratização das políticas públicas no Brasil.

\section{A área de estudo}

A Área de Proteção Ambiental do rio Pandeiros é uma Unidade de Conservação de uso sustentável e foi criada através da Lei 11.901 de 01/09/1995. Abrange áreas de interesse ecológico situadas na bacia hidrográfica desse rio, que tem uma extensão aproximada de $145 \mathrm{~km}$ (IEF, 2006). Está localizada na região Norte de Minas Gerais, ocupando parte dos municípios de Januária, Bonito de Minas e Cônego Marinho. Integra a bacia do rio São Francisco e sua administração está sob responsabilidade do IEF-MG, que atua na elaboração de projetos, na gestão e fiscalização (fig.. 1). 


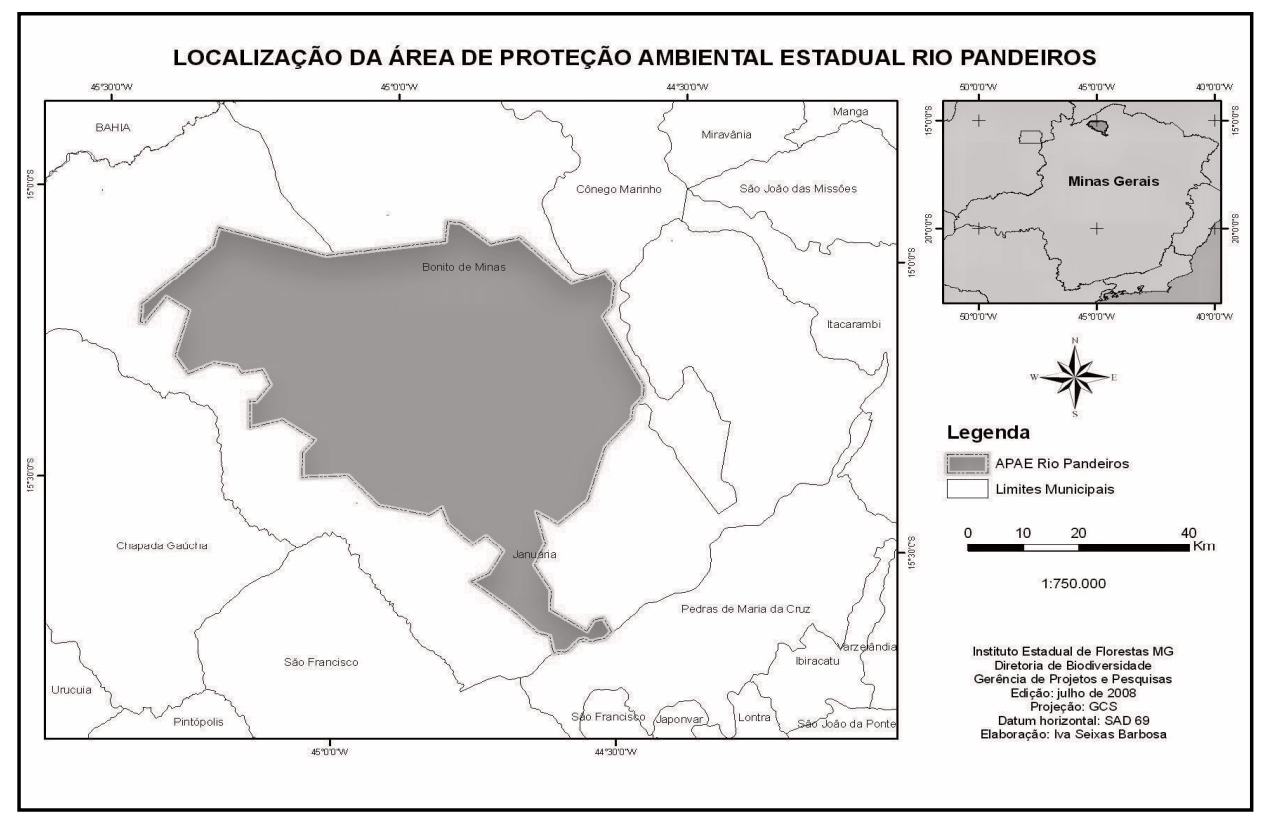

A legislação estadual considera uma Área de Proteção Ambiental APA, "a área assim declarada pelo Poder Público, para a proteção ambiental, a fim de assegurar o bem-estar das populações humanas e conservar ou melhorar as condições ecológicas locais" (Decreto $\mathrm{n}^{\circ}$ 33.944/92 - Art. $\left.5^{\circ}, \S 3^{\circ}\right)$.

Com uma área de 380.000 hectares ou $2.900 \mathrm{~km}^{2}$, limita-se com a Serra do Gibão (NO), com a Serra das Araras (SO), com o divisor de águas do rio Peruaçu até o São Francisco (NE) e com o divisor de águas da bacia do rio Pardo ao Sul (S-SO).

Considerado o "berçário do Velho Chico", o rio Pandeiros tornouse uma área de preservação ambiental (APA) com a inclusão da área de pântano, transformado em Refúgio de Vida Silvestre através do Decreto nº33.910, de 05/11/2004, com 6.102,75 ha. O objetivo da criação é preservar uma área de procriação de peixes. Além da beleza cênica do local, o rio Pandeiros é de importância decisiva para o ecossistema da região, sendo responsável por $70 \%$ da reprodução dos peixes que vivem no São Francisco entre as barragens de Três Marias (MG) e Sobradinho (BA). 
De acordo com a lei de sua criação algumas atividades estão restritas, como:

I - a realização de atividades que possam colocar em risco os mananciais e os campos alagadiços;

II - a execução de obras de terraplanagem e a abertura de canais, quando essas iniciativas importarem sensível alteração das condições ecológicas locais;

III - a realização de atividades capazes de provocar erosão de terras ou assoreamento de coleções hídricas;

IV - a realização de atividades que ameacem extinguir, na área protegida, espécies da biota regional;

V - a supressão total ou parcial de remanescentes de matas ciliares e de outras formações de matas naturais (Decreto $\mathrm{n}^{\circ}$ 33.944/92, Art. $5^{\circ}$ ).

A área da bacia do rio Pandeiros foi ocupada com mais intensidade em meados do século XVIII, com a formação das grandes propriedades rurais destinadas à pecuária de corte. A região teve sua paisagem modificada com mais intensidade nas décadas de 1960/70 e 1980, com a implantação de projetos de reflorestamento com eucalipto, visando à produção de carvão vegetal para atender à indústria siderúrgica. Segundo funcionário do IEF, a comunidade do Pandeiros

ganhou forças em dois momentos: com o FISET (Fundo que financiou o plantio de 1,5 milhões de hectares de eucalipto na região e que menos de $1 \%$ sobreviveu) e com o carvoejamento ilegal principalmente na última década (Sr. Walter Viana Neves. Entrevista em: 10 jan. 2008).

\section{Métodos e técnicas}

A estrutura conceitual foi realizada para compor um arcabouço teórico visando possibilitar a compreensão da dinâmica do território e as discussões a respeito de planos de manejo e gestão de Unidades de Conservação, bem como o papel do Estado nesse processo. 
Durante um primeiro momento de trabalho de campo foram verificadas as possibilidades de aplicação de entrevistas nas comunidades. A precariedade das vias de acesso apresentou-se como uma dificuldade no que se refere a um veículo capaz de transpor os obstáculos, como processos erosivos que já consumiram a estrada. Durante o trajeto, que ocorreu em veículo e com acompanhamento de funcionários do IEF, percebeu-se a presença de sacos de carvão aguardando transporte em várias partes, indicando a existência da atividade de carvoejamento.

O objetivo das entrevistas foi realizar a coleta de informações, identificando os problemas enfrentados no que se refere a viver em uma Unidade de Conservação. As entrevistas foram padronizadas, seguindo um roteiro previamente estabelecido, mas com a possibilidade de adaptação, uniformizando os dados para permitir comparações.

A identificação dos entrevistados ocorreu através de apontamentos dos funcionários do IEF e do guia contratado na comunidade, considerando-se a importância de entrevistar pessoas representativas, evitando um possível direcionamento por parte dos órgãos públicos.

As condições das estradas impediram a observação de todas as comunidades. Assim, elaborou-se um roteiro de forma a abranger parte expressiva da área. As comunidades foram identificadas com o auxílio dos Mapas Municipais Estatísticos - IBGE/2000, dos municípios de Januária e Bonito de Minas. As entrevistas foram realizadas nas comunidades de: Vila Pandeiros, Larga, Quilombo/Vereda, Poções/Angico, Várzea Bonita, Campos, além da cidade de Bonito de Minas e de lideranças em Januária.

Outro segmento entrevistado foi o de funcionários do IEF que atuam na área da APA Estadual do Rio Pandeiros. O roteiro da entrevista foi elaborado com o objetivo de identificar a atuação do IEF, os projetos existentes, as dificuldades e avanços alcançados nas relações com a comunidade.

Durante o levantamento de informações surgiu a necessidade de incluir mais duas entrevistas: com o líder da Colônia de Pescadores de Januária, com o objetivo de identificar os reflexos da situação ambiental da bacia hidrográfica do rio Pandeiros e sua relação com o rio São Francisco; e com a ONG Cáritas do Brasil, com o objetivo de compreender as dificuldades na implantação de projetos na região. 
O resultado desses procedimentos foi a verificação dos problemas na gestão da área, do ponto de vista dos moradores, do órgão gestor e de demais entidades de alguma forma envolvidas no processo.

\section{Resultados e discussão}

"Onde é que vamos viver?" Essa questão, proferida por um morador remete a reflexões sobre a situação da comunidade e sua importância para a real proteção da bacia hidrográfica do rio Pandeiros.

A Área de Proteção Ambiental Estadual do Rio Pandeiros tem sua história marcada por momentos em que a implantação de políticas públicas impôs novos direcionamentos ao território, com novos atores, objetos, interesses e ações, permeados por relações de poder. Nesse contexto a população das comunidades locais permaneceu excluída das discussões e dos benefícios dessas políticas.

Na década de 1970 a área recebeu reflorestamentos de eucalipto como parte do Programa Distritos Florestais, que teve como objetivo atender a demanda por carvão vegetal para a indústria siderúrgica mineira. Esses reflorestamentos foram realizados com a participação do Estado enquanto fornecedor de assistência técnica, mudas e incentivos fiscais, além da concessão das terras públicas. Duas décadas depois os contratos venceram e essas terras foram abandonadas. Em 1995 a área transformouse em uma Unidade de Conservação de uso sustentável com a gestão do Instituto Estadual de Florestas de Minas Gerais.

Essa parcela excluída da população é formada por pequenos produtores rurais e moradores da APA, porém compõe peça fundamental para o êxito de projetos que visam a sustentabilidade. Esse grupo deve ser pensado em suas interações com a natureza, a política, a economia e a cultura, em suas múltiplas relações de poder.

A agricultura familiar e a pecuária sempre foram a base da economia local. Mas a região de Januária passou por profundas transformações decorrentes da sua inserção em um mercado capitalista mais amplo, onde produtos antes comercializados nas feiras locais passaram a chegar de regiões distantes e com preços menores, pois são produzidos por grandes empresas, como é o caso do feijão e da farinha de mandioca. Com isso o quadro de carência dos pequenos produtores rurais 
se agravou, no momento em que perderam mercado e o que produziam não conseguia competir em preço com os produtos importados de outras regiões do estado ou do país.

Essa realidade se expressa na fala dos entrevistados

As pessoas comercializam na feira. A maior dificuldade para as pessoas da roça é vender o produto (Sr. Afonso. Presidente do Sindicato dos Trabalhadores Rurais de Januária. Entrevista em: 26 jul. 2007).

As pessoas cultivam e vivem desse cultivo. Usam para sobrevivência e vendem um pouco. Acham muito difícil, falta motivação. Eles vendem muito cachaça e rapadura (Sr. Eduardo. Comunidade da Larga. Entrevista em: 26 jul. 2007).

A gente faz farinha, sobra um pouco para vender, mas o preço é muito baixo - R $\$ 20,00$ o saco de 50 quilos (Sr. Santino. Carvoeiro em carvoaria na comunidade de Poções/Angico. Entrevista em: 29 jul. 2007).

A dificuldade não está apenas na comercialização, mas inicia-se no plantio, quando as condições do solo são desfavoráveis. Até o momento anterior à APA, muitos produtores usavam as áreas de veredas para o cultivo, mas atualmente existe a proibição. Os impedimentos ligados à legislação ambiental, fortalecidos pela presença do IEF, tornaram-se um ponto de insatisfação como demonstram os depoimentos:

A primeira dificuldade é que a maioria dos terrenos são fracos para trabalhar. As beiras dos rios e os brejos estão proibidos para plantar. Então dependemos de um incentivo grande para produzir e plantar, como o caso do biodiesel que vem aí, para plantar mamona. Se tiver um incentivo para essas pessoas, acredito que melhora. A EMATER arruma as sementes, de feijão, de horta. O pessoal é muito ignorante, querem fazer do jeito que faziam; precisa ter uma pessoa para ensinar. Tudo aqui para nós é difícil. Se planta uma lavoura, não acha quem compra; para vender melhor tem que ir para Chapada Gaúcha (cidade vizinha), quando vai para Januária, às vezes não vende. $\mathrm{O}$ forte aqui é a farinha de mandioca; com dois anos produz; vai vender um saco de farinha por $\mathrm{R} \$ 30,00$ e não 
acha quem compra. Um comércio de Januária compra 5 sacos de farinha. O que mais se produz é a farinha, pois a mandioca onde planta ela dá (Sr. Mário Silvério Viana. Líder comunitário de Várzea Bonita. Entrevista em: 25 jul. 2007).

O problema é que não tem lugar de plantar, como o caso do feijão. O terreno é fraco e não tem irrigação. Não falta água para uso, tem o rio Pandeiros que traz água encanada. Essas pessoas que cultivam não recebem apoio (Sr. José Francisco. Comunidade de Campos. Entrevista em: 25 jul. 2007).

A falta de apoio técnico em algumas comunidades da APA é um agravante da produção agrícola. Essa ausência gera a descrença da população nos órgãos do Estado. Dentre as sete comunidades visitadas para entrevistas, os representantes de cinco apontaram a ausência de assistência técnica para o cultivo. São elas: Vila Pandeiros, Larga, Vereda, Poções/Angico e Campos. Em algumas o IEF se faz presente, como na Larga, mas com projeto que não envolve todos os moradores, além de não destinar o apoio esperado para alternativas de cultivo.

Não recebem apoio de ninguém. Anteriormente conseguiam plantar nos brejos, feijão, milho, arroz, e hoje não conseguem mais pois acabou tudo, ficou tudo seco e a umidade é pouca. Eles comentam que cada ano que passa vai ficando mais difícil. O motivo é atribuído ao tempo, redução das chuvas (Sra. Geralda. Presidente da Associação Comunitária Amigos do Distrito do Pandeiros. Comunidade de Vila Pandeiros. Entrevista em: 28 jul. 2007).

Não existe a assistência técnica e com isso as pessoas desistem. Precisavam ganhar com a lavoura aquilo que ganhavam com o carvão (Sr. Oswaldino. Líder comunitário da Larga. Entrevista em: 11 jan. 2008).

Não tem assistência para plantar. A esposa recebe bolsa escola (Sr. Argemiro. Carvoeiro na localidade do Quilombo, próximo à comunidade da Vereda. Entrevista em: 10 jan. 2008).

Existe o apoio da EMATER, com um técnico. Está tentando fazer o projeto, mas depende das associações que estão 
endividadas e mal administradas e, por isso, não conseguem financiamento (não prestam contas e a Receita Federal barra tudo). Os sindicatos tentam ajudar. A principal fonte de renda do pequeno produtor é feijão, mandioca. Mas sobra pouco para a venda (Sr. Faustino Rodrigues da Silva. Ex-presidente do Sindicato dos Trabalhadores Rurais de Bonito de Minas. Entrevista em: 10 jan. 2008).

O quadro de carência só não está mais grave em decorrência dos programas do governo, que ofertam algum recurso para essa população, apesar das críticas de alguns moradores a esse tipo de programa social, que aparece como forma de suprir as deficiências da agricultura.

\begin{abstract}
A atividade foi importante para suprir a agricultura e muitas pessoas fizeram carvão. Mas hoje estão sem o plantio e sem o carvão. Recebem ajuda do governo, alguns tem emprego e outros arrumam bicos. Muitos jovens do Pandeiros estão indo trabalhar em Patrocínio e Brasília. A população jovem está indo embora. A população mais velha, que conseguiu se garantir na aposentadoria está ficando (Sra. Geralda. Presidente da Associação Comunitária Amigos do Distrito do Pandeiros. Comunidade de Vila Pandeiros. Entrevista em: 28 jul. 2007).
\end{abstract}

As pessoas daqui não estão preocupadas com isso, não ligam. Só estão preocupadas se tem a Bolsa Renda, Bolsa Escola, se já chegou na idade de 55 e 60 anos para aposentar. Antes de ter esses assuntos do governo (referindo-se aos programas sociais), o pessoal plantava mandioca, feijão, arroz, mas depois desses incentivos do governo, só tem aqui preguiçoso. As pessoas deixaram de trabalhar (Sr. Erondino. Comunidade de Várzea Bonita. Entrevista em: 25 jul. 2007).

Outra visão sobre os programas sociais é apontada pelo Sr. João Batista, funcionário da Cáritas do Brasil em Januária. Para ele existem problemas isolados, que de certa forma contribuem para as pessoas não trabalharem, mas são casos isolados. Além de uma redução na situação da fome, o trabalhador teve sua exploração reduzida 
é preciso saber que ainda existem muitas pessoas passando fome. Essa é a realidade. Por outro lado serviu para valorizar o trabalhador rural que era explorado por fazendeiros, que pagavam $\mathrm{R} \$ 5,00$ por tarefa. Hoje eles chegam para o fazendeiro e não aceitam. Tem dignidade. Dizem que o governo está pagando $\mathrm{R} \$ 15,00$. Por isso é que alguns falam que isso está servindo para deixar o pessoal preguiçoso ( $\mathrm{Sr}$. João Batista. Entrevista em 29 jul. 2007).

Os fatores apontados acima afetam diretamente a produção e comercialização agrícola. Esse quadro traz como consequência a produção de carvão enquanto alternativa de renda para essas pessoas. Mesmo conscientes dos impedimentos legais e do medo da multa, a produção persiste. $\mathrm{O}$ escoamento da produção ocorre sem dificuldades. Existem as áreas de desmates autorizadas pelo IEF com o objetivo de plantio de pastagem ou agricultura. Nessa situação o material lenhoso é aproveitado para o carvão. Tal fato foi verificado em campo, confirmando os relatos das entrevistas.

$\mathrm{Na}$ área da APA existem pontos onde o carvão é depositado, aguardando transporte (fig. 2). Segundo informações coletadas, nesses pontos misturam-se o carvão nativo com autorização ao clandestino.

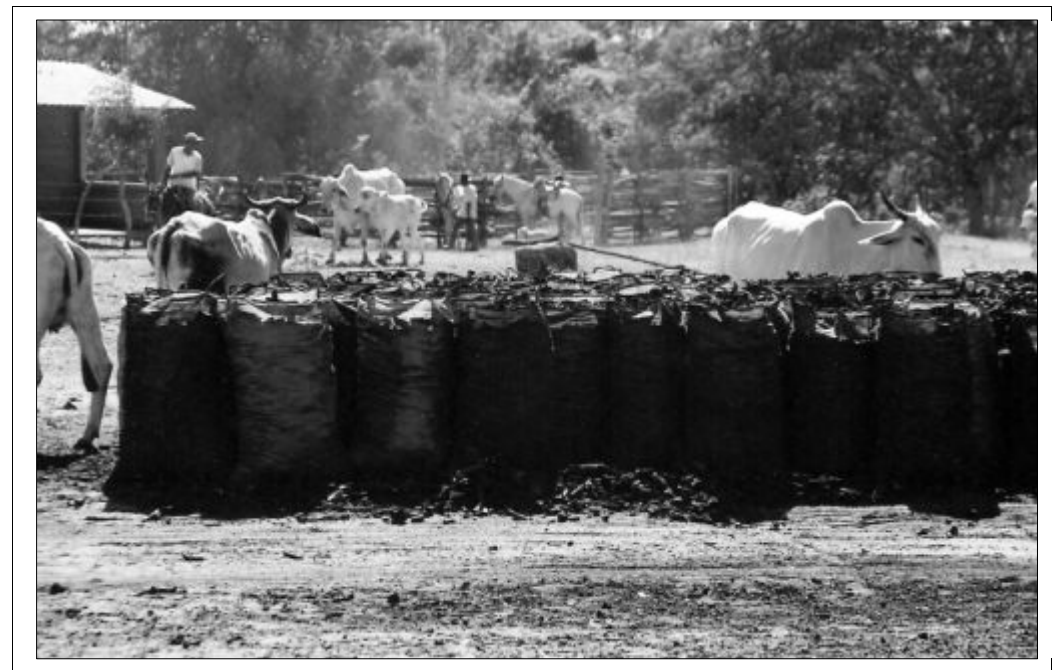

Figura 2: Carvão aguardando carregamento. Comunidade da Vila Pandeiros. 
Imagem em: 24 jul. 2007. Autoria: BETHONICO, M. B. de M.

Algumas famílias estão buscando alternativas de renda na coleta do babaçu para comercialização em Januária (figs. 3 e 4). O material é acumulado na estrada e um veículo faz o transporte até a olaria, onde é queimado no forno (figs. 5 e 6). Porém o valor para o produto é bastante reduzido. Um saco do fruto do babaçu, com peso de aproximadamente 20 quilos é vendido por $\mathrm{R} \$ 2,00$. Como apontam alguns moradores da comunidade, "não dá para viver de babaçu".
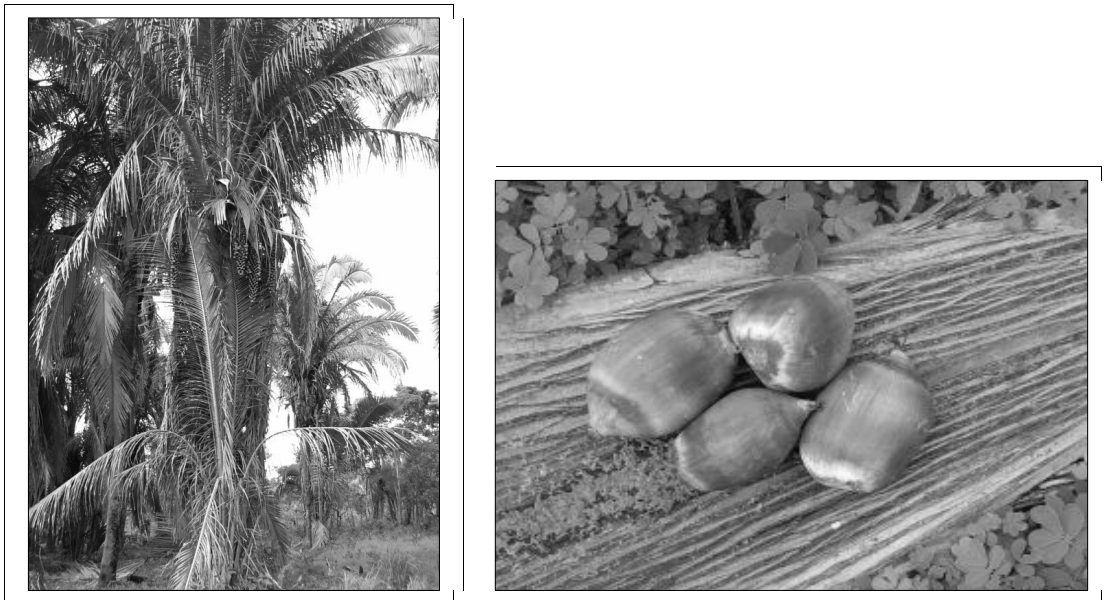

Figuras 3 e 4. Palmeira do babaçu e fruto - região de Bonito de Minas. Imagem em: 08 jan. 2008. Autoria: BETHONICO, M. B. de M.
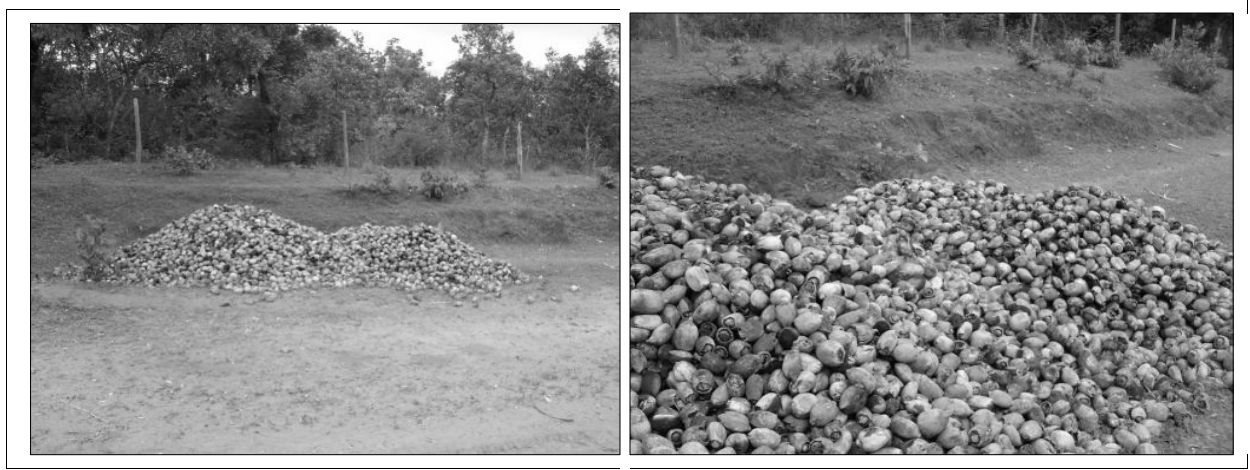
Figuras 5 e 6. Babaçu aguardando transporte - Bonito de Minas. Imagem em: 08 jan. 2008. Autoria: BETHONICO, M. B. de M.

O uso do babaçu indica que a comunidade do Pandeiros ainda percebe na natureza alguns elementos que se tornam recurso para a sobrevivência. A extração dos recursos naturais pela comunidade, sendo possível incluir o pequi que se destaca na época da coleta por seu valor comercial e aceitação no mercado, está ameaçada pela produção de carvão. A retirada da vegetação nativa para servir de matéria-prima aos fornos das siderúrgicas provoca o rompimento dos sistemas naturais, deixando um rastro de impactos no ambiente.

A comunidade demonstra a preocupação com a redução da água, com o esgotamento desse recurso em alguns lugares (fig. 7). A redução da água em algumas comunidades fez com que os córregos secassem totalmente, levando o morador a furar poços para conseguir água. Segundo depoimentos, esse é o caso do córrego Palmeira, na comunidade Vereda que teve sua cabeceira desmatada para a produção de carvão.

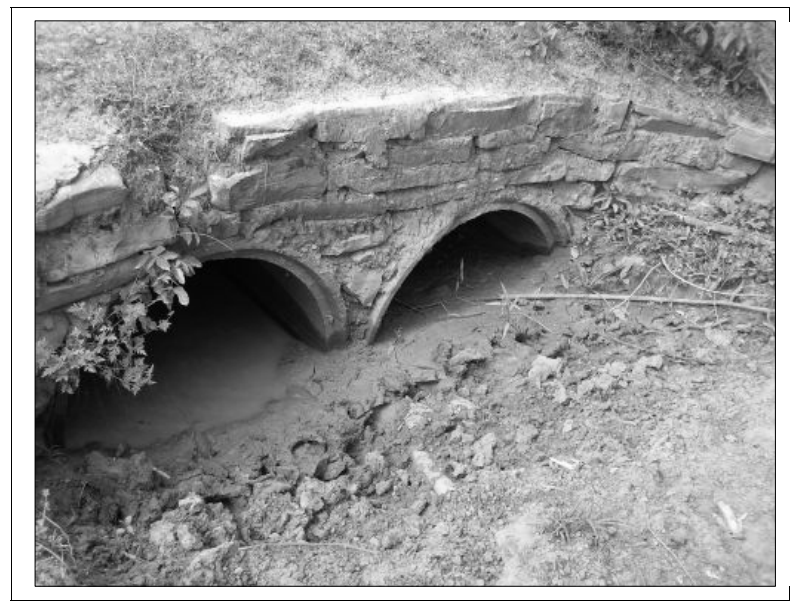

Figura 7. Córrego Maria Crioula - Estrada de acesso a Bonito de Minas. Imagem em: 08 jan. 2008. Autoria: BETHONICO, M. B. de M.

Os processos erosivos estão distribuídos por toda a bacia, decorrentes não apenas da extração da vegetação, mas da passagem dos 
caminhões que fazem o transporte (fig. 8). Algumas estradas estão intransitáveis, fato que causa transtornos para a comunidade que depende das estradas que ligam as cidades. $\mathrm{O}$ isolamento de algumas comunidades é agravado com a interrupção das vias de acesso.

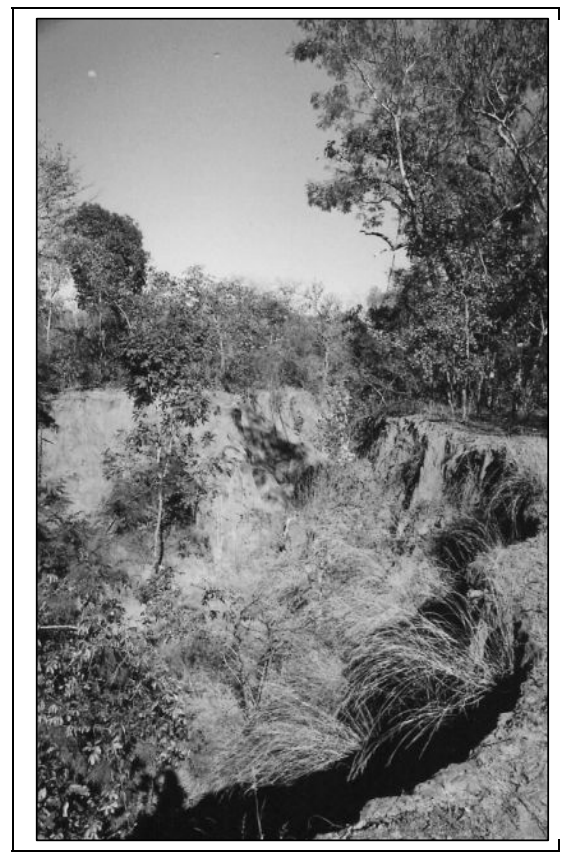

Figura 8. Processos erosivos na estrada - Comunidade Campos. Imagem de: jul. 2007. Autoria: BETHONICO, M. B. de M.

Outro fator essencial para a conservação da área é a participação da comunidade enquanto ator no processo de gestão. Segundo depoimentos, a comunidade não participou da definição da APA Estadual do Rio Pandeiros. Apesar da implantação ter ocorrido em momento posterior a algumas discussões amplas sobre a necessidade de participação das comunidades, como ocorreu na Conferência realizada no Rio de Janeiro Rio 92, optou-se ainda por manter uma visão de unidade de proteção limitada aos elementos bióticos e abióticos, desconsiderando os seres humanos e suas relações econômicas e com o meio ambiente. 
Também não foi considerado o espaço que ocupa e sua história, formada há alguns séculos. Essa UC obedeceu à prática de decisões "de cima para baixo", considerando a área como um "vazio demográfico" e os moradores mantiveram sua invisibilidade. $\mathrm{O}$ espaço foi reorganizado e o homem local, atônito, não viu alternativa a não ser adaptar-se ao novo gestor da área e de suas vidas - o Estado/IEF.

Que eu me lembre não fomos chamados para discutir a criação. No momento somos chamados, quando vai a liderança ou algum representante (Sr. Mário Silvério. Comunidade de Várzea Bonita. Entrevista em: 25 jul. 2007).

Antes de 1995 não chamaram para falar da APA. Criaram sem conversar. O IEF tem buscado recolher as ideias dos moradores e buscar soluções e ver o que precisam ( $\mathrm{Sr}$. Eduardo. Comunidade da Larga. Entrevista em: 26 jul. 2007).

Só falaram que iam fazer umas picadas, do Pandeiros para cá. As máquinas já estão ai. Iam cercar as terras do pântano para o gado e as pessoas não chegarem lá. Eu acho que esse povo aí está errado. Onde é que vamos viver? Nós não temos um cavalo, não podemos criar um gado, uma vaca para tirar o leite. Tudo isso nós falamos lá na reunião. Nós temos um pedacinho de cana para dar alimento para o gado no período da seca. Na seca a valência dos bichinhos é na beirada do rio, mas ai tapam lá e acabou (Sr. José Francisco. Comunidade de Campos. Entrevista em: 25 jul. 2007).

O Sr. José Francisco levantou um questionamento que, talvez, seja expressão comum (onde é que vamos viver?), demonstrando a exclusão da população na construção de uma proposta de gestão. Nas falas do Sr. Mário e Sr. Eduardo percebe-se que atualmente as pessoas são chamadas a participar das discussões, em uma situação de tentativa de reverter uma falha inicial.

\section{A busca de soluções}

O IEF tem buscado a solução para os problemas através de projetos. Um deles é o Projeto Pandeiros, que visa oferecer alternativa de renda aos moradores que fazem carvão. Entre eles encontram-se a Casa de Farinha, 
apicultura, agricultura e pecuária de pequeno porte e manejo florestal sustentável em pequenas propriedades.

Alguns resultados já foram apontados, como a ampliação da renda, de $\mathrm{R} \$ 50,00$ per capita mensal para $\mathrm{R} \$ 74,10$ nas comunidades que estão trabalhando com a coleta e beneficiamento do pequi. De acordo com a coordenadora do projeto, a bióloga Helen Duarte Faria, algumas ações previstas, como a educação ambiental, não se concretizaram.

A grande dificuldade na implantação dos projetos coordenados pelo IEF é a sua aceitação junto à comunidade. Ainda persiste a visão de um órgão voltado apenas para a fiscalização e aplicação de multas. A ONG Cáritas do Brasil iniciou esse projeto junto ao IEF, mas a parceria não prosseguiu. Segundo o Sr. João Batista

A Cáritas não tem problema com o IEF. Mas a questão é que em algumas áreas de atuação da Cáritas, as pessoas da comunidade não vêem o pessoal do IEF muito bem. Uma coisa é você chegar sozinho, da Cáritas, outra coisa é chegar junto com pessoas do IEF. A comunidade tem um olhar diferente. Em algumas comunidades esse trabalho funciona bem, como é o caso da Cabeceirinha (perto da Larga); tem outros que trabalham junto com o IEF e a Emater e tudo vai bem. Mas as coisas estão melhorando, aos poucos está ocorrendo uma aceitação (Sr. João Batista. Funcionário da Cáritas do Brasil em Januária. Entrevista em: jul. 2007).

Porém o tempo de uma política pública não é o mesmo da necessidade dos moradores que precisam do dinheiro para alimentação, vestuário, remédios, dentre outras, levando-os a desanimarem e buscar no carvão clandestino uma forma de sobrevivência.

A assistência é por parte do IEF, que tem um projeto muito bom, que é o Projeto Pandeiros. Mas atrasa muito e vem com as coisas fora de época; quando chegam com o calcário, com o adubo, já passou a chuva. Quando chega já não dá mais tempo de plantar e a chuva já foi embora, aí o pessoal não planta. Eles querem proibir de trabalhar no brejo, mas por enquanto o pessoal não pode parar porque precisam comer e, se não plantar não vão comer. (Sr. Eduardo, morador da 
comunidade da Larga - APA Estadual do Rio Pandeiros.

Entrevista em 27 jul.2007).

Essa assistência, a ser promovida pelo IEF, segue o disposto no Decreto 43.710/04, que regulamenta a política florestal e de proteção à biodiversidade. Segundo a legislação, em áreas de preservação permanente que contêm ocupação humana já consolidada e que não existe uma alternativa para remoção dessa comunidade, devem ser adotadas medidas mitigadoras e práticas culturais conservacionistas. Devem ser seguidos os critérios técnicos definidos pelo órgão competente, porém com respeito às peculiaridades locais. Em caso de alternativa de remoção, tal ação ocorrerá após o ciclo produtivo da cultura anual, devendo ficar a área para a regeneração natural ou através de plantio (Art. 11).

As ações lesivas ao meio ambiente serão punidas com advertências e multas (Decreto $\mathrm{n}^{\circ}$ 43.710/04, Art. 75), de forma cumulativa ou não. Essa função destinada ao IEF é um dos problemas enfrentados junto à comunidade, um gerador de conflitos.

Aos poucos o IEF tem buscado alterar sua posição frente às comunidades. Segundo o funcionário IEF que já trabalhou na APA, Sr. Walter Viana, o trabalho deve ser permanente e em vários locais, realizado por alguns funcionários mesmo com o baixo investimento e infra-estrutura disponibilizada pelo Estado.

Já foram feitas centenas de palestras e visitas e até mesmo gincanas em escolas públicas e associações comunitárias da região com esta finalidade, realizadas por equipe técnica do IEF e Corpo de Bombeiros. A proposta para modificar a situação é colocar as secretarias de agricultura e secretarias de ação social (municipal, estadual e federal) para funcionarem junto aos agricultores de subsistência. As secretarias acima citadas é que têm competência e preparação para resolver os problemas dos agricultores de subsistência. Os problemas ambientais são reflexos de uma utilização do solo sem sustentabilidade (Sr. Walter Viana. Entrevista em: abr. 2008).

A relação com os pescadores é, também, alvo do trabalho do IEF na região. Segundo o depoimento do Sr. Simião, o relacionamento com o IEF 
varia muito de região para região. Aqui não existe problema. Existe uma parceria com a guarda florestal. Defendo a tese de que trabalhar em parceria é melhor. Já temos uma relação legal com o engenheiro de pesca que ajuda no que diz respeito à pesca. Existe lugar em que o presidente coloca que o IEF é prejudicial; criticam que fecham a pesca e não existe uma contrapartida e o pescador fica sem renda de uma hora para outra. Com a criação da APA e do Refúgio melhorou o relacionamento do pescador com a polícia ambiental, com bate-papo e respeito entre eles. Com isso os pescadores ficaram mais conscientes. Antes os cardumes do pântano eram menores. Agora já dá para notar que aumentou bastante o volume de peixes, subindo o rio com dia de sol claro dá para ver surubim no fundo. $\mathrm{O}$ dourado, que mais reproduz no Pandeiros, aumentou bastante a quantidade no rio, mesmo com todo o assoreamento. Mas não dá para dizer que a causa seja a criação da área de proteção ambiental (Sr. Simião Reginaldo. Presidente da Colônia de Pescadores de Januária. Entrevista em: 10 jan. 2008).

As dificuldades não estão apenas nas ações do IEF. Outras entidades encontram barreiras políticas e culturais

é um desafio criar cooperativas para escoar os produtos, ainda mais agora que os grupos de produtivos de economia solidária já começaram a produzir, nosso receio é que essa produção não tenha mercado e a pessoa desacreditar. Nós enchemos eles de ânimo, mas esperamos que os produtos (orgânicos) tenha aceitação no mercado. Temos muita resistência de algumas pessoas, das famílias, mas principalmente, por conta de nossa instituição não ser bem vista pelos políticos, pois fazemos um trabalho de formação e conscientização, em todos os sentidos. Nós somos os facilitadores dessas comunidades, mas para eles serem agentes. Quase sempre tem essa interferência política, que repercute muito mais que o fato de sermos pessoas de fora, por que as pessoas estão acostumadas com as questões da política, essa politicagem; as vezes tem um político que é vereador, irmão do prefeito, etc., que não faz nada pela região; chega na época da política, faz 
uma festa, mata um boi, dá um jogo de camisa para um time de futebol e ganha o povo de novo. Nós chegamos mostrando para eles uma outra visão; mostrando o que é o dever, o que eles têm que realmente fazer diante disso tudo, diante desse coronelismo que ainda impera aqui na região. Esse é um desafio. As novas lideranças, mais jovens, já estão com uma nova visão (Sr. João Batista. Funcionário da Cáritas do Brasil. Entrevista em: jul. 2007).

Muitos funcionários do IEF acreditam nos projetos e trabalham para sua concretização. Porém problemas burocráticos, de recursos e de falta de segurança contribuem para o prejuízo do trabalho e a descrença da comunidade.

\section{Considerações finais}

A Lei ${ }^{\circ} 9.985 / 2000$, que criou o SNUC, propõe a participação das comunidades locais, além de um trabalho de educação ambiental. Porém apenas a lei não basta. Quando se define uma Unidade de Conservação define-se, também, a vida das pessoas que ali se encontram. A nova forma de vida imposta pela legislação ambiental e a gestão do Estado não são apenas sobre os recursos naturais e sobre o território, mas sobre a vida da comunidade. Porém, essas pessoas são excluídas dos processos, fato que impede a gestão eficiente de uma área de preservação. Por outro lado uma APA deve ser pensada, também, como um mecanismo fundamental para a proteção de outras unidades de proteção integral, como o caso aqui estudado, onde a APA Estadual do Rio Pandeiros tem papel impar na preservação do pântano que, por sua vez, contribui efetivamente para a manutenção dos peixes do rio São Francisco.

Os projetos elaborados e que estão em execução pelo IEF têm esbarrado na burocracia, demonstrando um descompasso entre as necessidades reais da população e a necessidade de preservação. Percebese que a comunidade não é contrária às questões de preservação ambiental, porém a necessidade de sobrevivência se sobrepõe. Os problemas são muitos e a comunidade aguarda soluções, principalmente no que se refere a uma ausência de ações concretas, como assistência técnica para melhorar a 
produção agrícola, vias de acesso em boas condições para escoamento da produção e comercialização.

A participação efetiva dos moradores no processo de gestão é o passo inicial para solucionar esses problemas, pois eles se envolvem mais e, juntos, buscam soluções práticas para as questões que os preocupam. Por outro lado, a melhoria das condições de cultivo, transporte e comercialização eleva a qualidade de vida das pessoas que ali residem, reduzindo a necessidade de buscar outros lugares para viver.

Assim, repensar e planejar o território deve ser tarefa coordenada pelo Estado com a participação da sociedade que se torna assim um parceiro. O caso aqui estudado indica o descompasso entre a criação de UCs e a efetivação das políticas estruturadoras direcionadas para a gestão dos conflitos e de estrutura humana e material dos órgãos responsáveis por essa gestão, como o IEF-MG.

Diante das dificuldades e avanços, é importante considerar que a elaboração de políticas públicas não deve ocorrer de forma autoritária. Existe a expectativa de adoção de um planejamento compartilhado entre Estado e sociedade, com a construção de pactos e compromisso que tenham como finalidade promover a transformação social, garantindo com isso a sustentabilidade social e ambiental da APA Estadual do Rio Pandeiros.

\section{GESTÃO SUSTENTÁVEL DE UNIDADES DE CONSERVAÇÃO: O CASO DA APA ESTADUAL DO RIO PANDEIROS, MINAS GERAIS}

Resumo: A eficiência dos planos de manejo de Unidades de Conservação é um dos principais problemas quando a questão é a conservação, acompanhada da preservação do meio ambiente. O presente artigo examina um dos problemas na implantação dos planos e gestão desses espaços: a não participação das comunidades. Para tal destaca a visão dos moradores e a relação com o órgão gestor, apontando para a não participação e os principais problemas que enfrentam para a sobrevivência em uma Unidade de Conservação, a APA Estadual do Rio Pandeiros, que está inserida em uma das regiões mais pobres de Minas Gerais. Em outro momento são avaliadas as ações do órgão gestor e as dificuldades que encontram na implementação de seus projetos. Dessa forma pretende-se contribuir para as discussões sobre a gestão dessas áreas, apontando 
para a importância da participação da comunidade que se torna parceira no processo.

Palavras-chave: Gestão, Unidade de Conservação, Participação da comunidade.

\section{SUSTENTABILITY MANAGEMENT OF CONSERVATIONS UNITS:} THE CASE OF APA ESTADUAL DO RIO PANDEIROS, MINAS GERAIS

Abstract: Efficiency of stewardship plans of conservation units is one of the main problems when the issue is environment conservation and preservation. This article examines one of the problems in the deployment plans and management of such spaces: the non-participation of the communities. It highlights the vision of residents and the relationship with the Department Manager, pointing to the nonparticipation and the main problems facing for survival in a conservation Unit, the APA Estadual do Rio Pandeiros, which is inserted into one of the poorest regions of Minas Gerais. At another part we have evaluated the actions of the body and Manager of the difficulties that are implementing their projects. So, we intend to contribute for discussions on the management of these areas, pointing to the importance of community participation that becomes a partner in the process.

Keywords: Management, Unit of Conservation, Community Participation

\section{Bibliografia}

AMARAL, W. A. N.; BRITO, M. C. W.; ASSAD, A. L. D.; e MANFIO, G. P. Políticas públicas em biodiversidade: conservação e uso sustentado no país da megadiversidade. Disponível em:

$<$ http://www.hottopos.com/harvard1/politicas_publicas_em_biodiversi.htm >. (acesso em: 08 dez. 2007).

FGV. 1986. Dicionário de Ciências Sociais. Rio de Janeiro: Editora da FGV. 1422 p.

GUILHON, M. V. M.; PEREIRA, M. E. F. D. 2001. Algumas considerações sobre a noção de eficiência nas políticas públicas. Revista de Políticas Públicas, São Luiz, v. 6, n.2, p. 103-126. 
INSTITUTO ESTADUAL DE FLORESTAS/IEF. 2006. Bacia do Rio Pandeiros. Januária: Instituto Estadual de Florestas,. 5f. Mimeografado.

MOREIRA, R. 2006. Para onde vai o pensamento geográfico? Por uma epistemologia crítica. São Paulo: Contexto. 191 p.

MORSELLO, Carla. 2001. Áreas protegidas públicas e privadas: seleção e manejo. São Paulo: Annablume: FAPESP. 344p.

SANTOS, Milton. 2002. A natureza do espaço: técnica e tempo, razão e emoção. São Paulo: Editora da Universidade de São Paulo.

SOUZA, M. J. L. 2001. O território: sobre espaço e poder, autonomia e desenvolvimento. In: CASTRO, I. E. C. et al. (org.). Geografia: conceitos e temas. 3.ed. Rio de Janeiro: Bertrand Brasil. 352p.

STEINGERGER, M. et al. (Org.). 2006. Território, ambiente e políticas públicas espaciais. Brasília: Paralelo 15 e LGE Editora. 408 p.

VALLEJO, L. R. 2005. Políticas públicas e conservação ambiental: territorialidades em conflito nos parques estaduais da Ilha Grande, da Serra da Tiririca e do Desengano (RJ). Orientadores: Carlos Alberto Franco da Silva e Cláudio Belmonte de Athayde Bohrer. 342 p. Tese (Doutorado em Geografia). Instituto de Geociências da Universidade Federal Fluminense, Niterói. 